\title{
SHERPA Technique as an Approach to Healthcare Error Management and Patient Safety Improvement: A Case Study among Nurses
}

\author{
Mohammad Khandan, ${ }^{1}$ Saeedeh Yusefi, ${ }^{2}$ Robabeh Sahranavard, ${ }^{2}$ and Alireza Koohpaei ${ }^{3,}$ \\ ${ }^{1}$ MSc in Ergonomics, Ergonomics Department, Health Faculty, Qom University of Medical Sciences, Qom, IR Iran \\ ${ }^{2}$ Student Research Committee, Qom University of Medical Sciences, Qom, IR Iran \\ ${ }^{3} \mathrm{PhD}$ in Occupational Health, Occupational Health Department, Health Faculty, Work Health Research Centre, Qom University of Medical Sciences, Qom, IR Iran \\ "Corresponding author: Alireza Koohpaei, PhD in Occupational Health, Occupational Health Department, Health Faculty, Work Health Research Centre, Qom University of \\ Medical Sciences, Qom, IR Iran. Tel: +98-2537835522, +98-9122522066, Fax:+98-2537833361, E-mail: koohpaei19@yahoo.com
}

Received 2016 February 27; Revised 2016 June 13; Accepted 2016 October 13.

\begin{abstract}
Background: Overcoming the challenge of human error occurrence in the healthcare section and patient safety improvement is impossible without understanding the nature of human error and without considering the fundamentals of human factors and ergonomics in designing and implementing sociotechnical systems. Therefore, the first step is to identify medical errors and their causes, using standard methods.

Objectives: The aim of this study was to identify and evaluate human errors among nurses in the women's infectious diseases ward in an educational hospital in the city of Qom in 2015.

Methods: This cross-sectional study was performed to identify the medical errors among sixteen female nurses working in the women's infectious diseases ward, using SHERPA. Hierarchical task analysis (HTA) was performed; errors were identified by checklist and risk assessment was then carried out.

Results: One hundred fifty-nine errors were identified and evaluated in 89 tasks. Most of the detected errors were of the action type (74.21\%) and the least errors were of the selection type(0.63\%). The least number of the errors' risk level was placed in the undesirable, and the highest was in the unacceptable level.

Conclusions: Since the majority of the errors were of the action type, proper measures should be taken to prioritize them in disease control. In addition, designing a treatment process based on human factors and ergonomic principles is highly recommended to enhance the quality of services, improve patient safety and reduce errors. With respect to task analysis, the SHERPA is a good technique to evaluate and monitor medical errors.
\end{abstract}

Keywords: Medical Error, Human Factors, SHERPA, Patient Safety, Macro-Ergonomics

\section{Background}

Although humans are smart, adaptable and have the ability to learn over time, they are prone to errors (1). Working in a healthcare environment is multitask, and depends on an efficient communication between those involved in the healthcare system, and on the manner in which the system is being managed (2). With respect to the complexity and dynamic job duties, nursing is unique and high workload is one of the major complaints of the nurses (3). This could impose major risks on patient safety (4); and as a result, mortality, prolonged hospital stay and medical costs would sharply increase (5). Patient safety is one of the most important issues in the healthcare system worldwide (6). An error is defined as a deficit created in the process of care, which results in patients' major injury, or the one that has the potential to create such damages (7). Errors are of the most frequent causes of death and preventable complications in hospitals (8). Although nurses do not work apart from the whole system, and are the last part of the chain of care (9), more than $40 \%$ of their working time is directly involved in the implementation of health instructions (10). Therefore, committing errors when they are performing their tasks is typical (11). Applying the wrong dosage of medication and failure to comply with doctor's prescription are examples of common errors among nurses in the healthcare environments (12). Evidence indicates that the level of medical errors in spite of all corrective actions has remained high (13). Between 44 to 98 thousand patients in the United States die due to preventable medical errors, and around one million injuries caused by medical errors is recorded annually (14). According to a study in the UK, changing the shift, lack of access to patient information, lack of experience, high workload, illegible handwriting, incomplete knowledge and skills, computational errors and faults in computer data entry were among the main causes of errors (15). A study in Australia showed that about $17 \%$ of all the cases admitted to the hospital led to an unwanted complication, half of which were preventable (16). Medical errors affected 85,000 people in the UK annually, 
leading patients to stay two more days in health facilities $(17,18)$. In France, 10,000 deaths are associated with medical errors annually (19).

According to Bandura's theory, different factors can be attributed to medical errors (4), some of which are as follows: Fatigue (20), quality of working life (21), age (22), educational level (23), adherence to safety criteria (24), experience (25), leadership and organization (26), organizational structure (27), the demographics of patients (28) and shift working (29). In addition, medical errors have been ranked high in developing countries (5). Due to the poor reporting systems as well as complicated legal requirements to create a database, no exact figures are available in developing countries. However, according to court records, number of errors is high (30). In Iran, a study revealed that $16.7 \%$ of the nurses committed medical errors, and the most common were omission of some prescribed medications and inappropriate application of medications (31). In another study, $64.5 \%$ of Iranian nurses confessed that they had medical errors (32). In another research, $46.8 \%$ of the nurses in the emergency room of a teaching hospital in Tehran had errors within a year; of them, $69 \%$ were observed to have had at least one error during their nursing career (33).

Undoubtedly, one of the ways to improve patient safety is to distinguish medical errors and their causes. Among the methods available to identify and assess error, systematic human error prediction and reduction technique (SHERPA) is one of the most common ones to survey error. SHERPA method has more advantages compared to other methods of identifying human error (34) and is recommended for handling errors in healthcare processes and systems (35). Although the use of SHERPA is common in the industrial sector (36-39), in Iran published studies on human errors in healthcare centers were limited to areas such as surgery process (34), the duties of nurses in the emergency department $(35,40)$, ICU (41), and the duty of physicians in the emergency department (42).

\section{Objectives}

The aim of this study was to assess the types and causes of errors among the nurses and offer practical solutions to manage the tasks of the nurses and reduce the incidence of medical errors in the women's infectious diseases ward in a teaching hospital in Qom, using the SHERPA method.

\section{Methods}

This cross-sectional study was conducted to identify and manage human errors of the nurses in the women's infectious diseases ward in 2015. Sixteen female nurses were working in three shifts and were involved in the following activities: Administering drugs, injections, dressing, getting an EKG, checking the body temperature, measuring blood pressure, checking pulse rate, measuring blood sugar levels, and dealing with open and infectious wounds. Patients' information was entered into a comprehensive system at admission, and after they were transferred to the wards, their conditions were checked and recorded. In this study, SHERPA was used to evaluate errors (37). The method's reliability and validity have previously been approved $(17,43,44)$. This method was also applied in healthcare sections in Iran and proved useful in recognizing errors $(35,40,42)$. SHERPA could be adapted to various ward settings, and researchers could use it for a range of different healthcare procedures (17). In this study, SHERPA involved nine steps (Table 1 ).

Table 1. Steps of SHERPA Technique

\begin{tabular}{|lll}
\hline Step & Title & Description \\
\hline One & Hierarchical task analysis & $\begin{array}{l}\text { Task/sub-tasks analysis by } \\
\text { interviews and observation }\end{array}$ \\
\hline Two & Task classification & $\begin{array}{l}\text { Dividing tasks based on the } \\
\text { behavior taxonomy }\end{array}$ \\
\hline Three & Human error identification & Using error code \\
\hline Four & Consequence analysis & $\begin{array}{l}\text { Examining the consequences of } \\
\text { each error }\end{array}$ \\
\hline Five & Recovery analysis & $\begin{array}{l}\text { Which action is necessary to error } \\
\text { prevention }\end{array}$ \\
\hline Six & Ordinal probability analysis & $\begin{array}{l}\text { The probability of the error is } \\
\text { determined }\end{array}$ \\
\hline Seven & Criticality analysis & $\begin{array}{l}\text { The severity of damage caused by } \\
\text { error is determined }\end{array}$ \\
\hline Eight & Remedy analysis & $\begin{array}{l}\text { Practical ways to control and } \\
\text { prevent error }\end{array}$ \\
\hline Nine & Tabulation & SHERPAs worksheets \\
\hline
\end{tabular}

${ }^{\mathrm{a}}$ Types of errors included action, checking, retrieval, communication and selection errors.

In this study, the research team referred to the ward at different times within a day to observe the nurses' performances as well as the conditions of the patients. After conducting interviews and providing the necessary explanations about aims of the study, the research team members collected the data on the activities of the nurses. Then SHERPA's worksheets were completed. Tasks were classified and other items of the including including the codes of the errors, error descriptions, consequences of the errors, recovery, level of risk and corrective actions were completed for specified tasks based on the worksheets. The risk level of the errors contained probability (frequent, probable, occasional, remote and improbable) and severity (catastrophic, critical, marginal and insignificant) (Ta- 
ble 2). The results were examined with the cooperation of a number of nurses of the ward. The analysis was performed after the final verification of the worksheets.

\section{Results}

One hundred fifty-nine errors related to the studied tasks (89 cases) were identified in the infectious diseases ward. According to Table 3, the highest number of recorded errors was reported as action type, and the lowest number of errors, which occurred in the infectious diseases ward, was the selection type. The frequency of nursing errors in terms of risk level is demonstrated in Table 4.

Based on the results (Table 4), 5.66\% of the medical errors ( 9 errors) had an unacceptable risk level (high), $38.36 \%$ (61 errors) had undesirable risk level, 32.07\% (50 errors) had an acceptable risk level, with a need for corrective acts (Medium), and 23.9\% (38 errors) had acceptable risk level with no needs for corrective acts (Low). The highest number of errors was reported in those with undesirable risk level, and the lowest number was in those with unacceptable risk level. Among the unacceptable errors, action errors (77.78\%) had the highest frequency, followed by communication errors with the rate of $22.22 \%$. In addition, among the errors with undesirable risk level, action errors (62.29\%) and communication errors (31.14\%) were the most frequent. Moreover, errors with the greatest probability were identified based on SHERPA technique.

The most important errors were as follows: Forgetting to assess the patient's breathing conditions at admission, with the risk level of 3A (unacceptable); errors in assessing the patient's pulse, with the risk level of $3 \mathrm{~B}$ (undesirable); improper closing of the cuffs in dresses, with the risk level of $4 \mathrm{~A}$ (acceptable with a need to redesign); lack of ECG lubricant gel, with the risk level of 3B (undesirable); no masking, with the risk level of $2 \mathrm{~B}$ (unacceptable), and no hand washing or disinfection, with the risk level of $3 \mathrm{~B}$ (undesirable). Moreover, errors with greater severity were recorded, including no replacement of the catheter in standard intervals,with the risk level of $2 \mathrm{D}$ (undesirable); failure to register the patient's condition in terms of previous surgeries and diseases, with the risk level of $2 \mathrm{E}$ (acceptable but needing a redesign of actions); no measurement of blood sugar in patients, with the risk level of $2 \mathrm{D}$ (undesirable); failure to register the patient's chest pain when taking ECG, with the risk level 2C (undesirable); and and lack of timely suction with the risk level of 2D (undesirable). The number of credible errors in SHERPA and an example of the filled worksheet of SHERPA in the studied wards are displayed in Tables 5 and 6, respectively.

\section{Discussion}

As demonstrated in Tables 3 and 5, action errors accounted for the highest frequency (74.21\%), similar to findings of other researchers in the healthcare section $(41,42)$ and industries (36). Since most of the activities of the nurses in hospitals involve clinical procedures, lack of an appropriate implementation of guidelines and improper drug usage, or treatment communication with the registered patients may lead to the incidence of errors in the form of the action type (35). In this study, the lowest number of errors was identified in the selection type. Mohammadfam et al. also found similar results in a therapeutic process (34). The only reported error that represented the selection error type was the application of catheter with a wrong number. However, this selection error had acceptable risk level. Given that the nurses do not need to make as much decisions as the physicians, this condition was acceptable. Furthermore, Lane et al. designed a research, using the SHERPA technique to identify pharmaceutical management errors in a hospital (17). In their study, the most frequent errors were of the action type and the least frequent were of the selection type.

Based on the obtained data, it was revealed that action errors were in the first line of errors, which is in line with findings of the previous studies (17), followed by communication errors as the most frequent errors (Table 5). Furthermore, a study conducted (using the SHERPA technique) among nurses in an Iranian hospital revealed that action errors were the most frequent, followed by retrieval errors $(35,42,45)$.

In this study, undesirable errors dominated all other types, similar to some other studies $(35,42)$. On the other hand, Kermani et al. reported errors that were acceptable but needed corrections as the most frequent errors (40). These types of errors were consistent with the types of nurses' tasks in the infectious diseases ward. Communication errors usually occurred between the nurses and patients and between the nurses and patients' families during the admission process. The nurses' errors could be due to work overload or the lack of sufficient time to obtain valid and reliable information. The personnel of the infectious diseases ward encountered more workloads in their quest to maintain and support the epidemic of diseases (e.g., influenza), especially in certain seasons. It is anticipated that an increase in patients' admission process and the high workload of the personnel generally increase errors, particularly action errors. To prevent this, it is recommended that more personnel be recruited based on a predefined plan.

According to Table 4, although action errors accounted for the highest frequency of errors, communication er- 
Table 2. Risk Level Matrix for Application in the SHERPA Technique ${ }^{\mathrm{a}}$

\begin{tabular}{|c|c|c|c|c|}
\hline Risk & Catastrophic & Critical & Marginal & Insignificant \\
\hline Frequent (A) & $1 \mathrm{~A}$ & $2 \mathrm{~A}$ & $3 \mathrm{~A}$ & $4 \mathrm{~A}$ \\
\hline Probable (B) & 1B & $2 \mathrm{~B}$ & 3B & $4 \mathrm{~B}$ \\
\hline Occasional (C) & $1 \mathrm{C}$ & $2 \mathrm{C}$ & $3 C$ & $4 \mathrm{C}$ \\
\hline Remote (D) & $1 \mathrm{D}$ & $2 \mathrm{D}$ & $3 \mathrm{D}$ & $4 \mathrm{D}$ \\
\hline Improbable (E) & $1 \mathrm{E}$ & $2 \mathrm{E}$ & $3 \mathrm{E}$ & $4 \mathrm{E}$ \\
\hline
\end{tabular}

${ }^{\text {a }}$ Shading indicates the highest risk level.

Table 3. Description of Tasks and Identified Errors Based on the Hierarchical Task Analysis (HTA) ${ }^{a}$

\begin{tabular}{lcccccc}
\hline & & \multicolumn{3}{c}{ Categories } \\
\cline { 2 - 6 } & Action & Checking & Retrieval & Communication & Selection & Total \\
\hline Errors & $118(74.21)$ & $8(5.03)$ & $7(4.40)$ & $25(15.72)$ & $1(0.63)$ & $159(100)$ \\
Tasks & $65(73.04)$ & $4(4.49)$ & $4(4.49)$ & $15(16.86)$ & $1(1.12)$ & $89(100)$ \\
\hline
\end{tabular}

${ }^{\mathrm{a}}$ Values are expressed as No. (\%).

Table 4. Description (N(\%)) of Identified Errors based on the Risk Level

\begin{tabular}{|c|c|c|c|c|c|}
\hline \multirow{3}{*}{ Risk Type } & \multicolumn{5}{|c|}{ Risk Criteria } \\
\hline & \multirow{2}{*}{$\begin{array}{c}\text { Low } \\
\text { Acceptable }^{a}\end{array}$} & \multirow{2}{*}{$\begin{array}{c}\text { Medium } \\
\text { Acceptable }^{\mathrm{b}}\end{array}$} & \multicolumn{2}{|c|}{ High } & \multirow[b]{2}{*}{ Total } \\
\hline & & & Undesirable $^{c}$ & Unacceptable $^{d}$ & \\
\hline Action & $32(27.12)$ & $41(34.74)$ & $38(32.2)$ & $7(5.93)$ & $118(100)$ \\
\hline Checking & $3(37.5)$ & $5(62.5)$ & 0 & 0 & $8(100)$ \\
\hline Retrieval & 0 & $3(42.86)$ & $4(57.14)$ & 0 & $7(100)$ \\
\hline Communication & $2(8)$ & $2(8)$ & $19(76)$ & $2(8)$ & $25(100)$ \\
\hline Selection & $1(100)$ & 0 & 0 & 0 & $1(100)$ \\
\hline Total & $38(23.90)$ & $51(32.08)$ & $61(38.36)$ & $9(5.66)$ & $159(100)$ \\
\hline
\end{tabular}

${ }^{a}$ Error: Occurred, No Harm to the Patient.

b Increased need for monitoring, no change in vital signs or transient change in vital signs, No harm to the patient.

${ }^{c}$ Increased monitoring, change in vital signs - treatment needed, change in length of stay or effect on an investigational drug protocol.

${ }^{\mathrm{d}}$ Increased monitoring and treatment, change in patient morbidity or death.

rors were of comparatively smaller percentage, as some of them were in the undesirable and unacceptable risk levels (38.13\% vs. $84 \%$ ). Therefore, it seems that communication errors, in addition to action errors, were important in infectious diseases wards and should be considered as a priority. Although many studies have signified the importance of teamwork in reducing action errors $(36,46)$, it should be noted that ambiguity increases communication errors in a team. In a study conducted on Swedish nurses, it was revealed that about $69 \%$ of the errors were related to teamwork (2). Nowadays, nursing is considered as a complex and dynamic job, which needs creativity and decision-making in undoubtedly difficult situations (47).
In addition, contributing factors in the incidence of errors are multifactorial and related to people, teams and their organizations. In such circumstances, implementation of a root cause analysis (RCA) is recommended. Moreover, designing an effective analysis may help develop a proper system of record keeping and reporting as well as follow-up of the errors and internal investigation. For this purpose, the conceptual framework for error classification was suggested by WHO and the European Union (48).

In our study, which is similar to others (49), errors such as failure of recording vital signs and medications of the high risk patients were identified as common errors. Hence, addressing and redesigning this type of er- 
Table 5. Number of Credible Errors in SHERPA

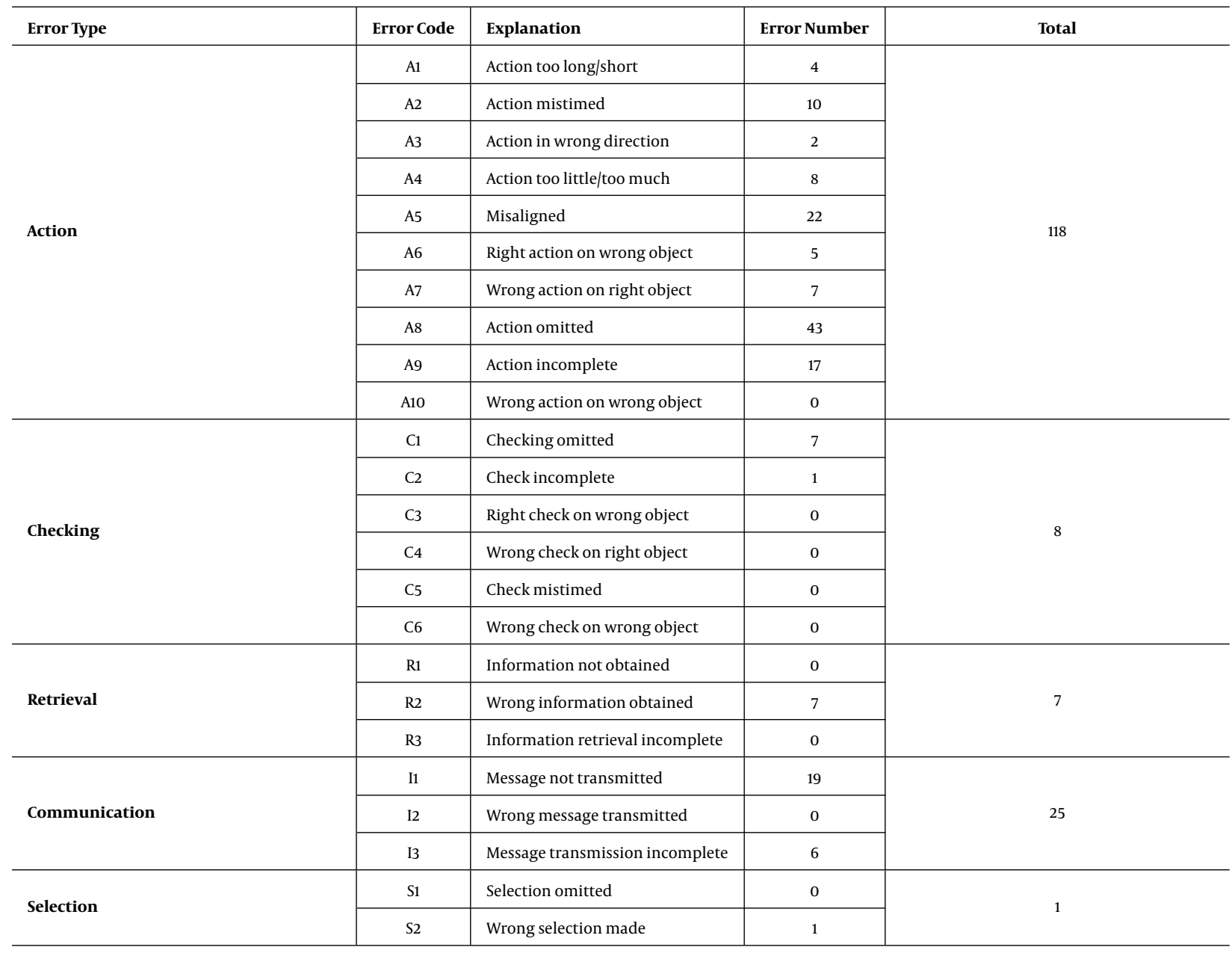

Table 6. An Example of SHERPA Technique's Worksheet in the Studied Infectious Diseases Ward

\begin{tabular}{|c|c|c|c|c|c|c|}
\hline Task Step & Error Code & Description & Consequence & Recovery & Risk Level & Remedial Measure \\
\hline 1.1.1 & A8 & Fail to start infusion & No drug given & & $3 \mathrm{~B}$ & Training \\
\hline 2.1.1 & $\mathrm{C} 1$ & $\begin{array}{l}\text { Fail to check the volume of } \\
\text { medication in syringe }\end{array}$ & Overdose & & $2 \mathrm{C}$ & $\begin{array}{l}\text { Training in administering } \\
\text { injections }\end{array}$ \\
\hline 3.1.1 & $\mathrm{R}_{2}$ & Read drug name incorrectly & $\begin{array}{l}\text { Selection of wrong drug for } \\
\text { administration }\end{array}$ & 3.1.3 & $1 \mathrm{~B}$ & $\begin{array}{l}\text { Indicate the patient condition } \\
\text { the drug is prescribed for }\end{array}$ \\
\hline 3.1.2 & $\mathrm{R}_{2}$ & Read drug dose incorrectly & $\begin{array}{l}\text { Administration of overdose or } \\
\text { dose of no therapeutic value }\end{array}$ & 3.1.3 & $2 \mathrm{~B}$ & $\begin{array}{l}\text { Only use standard abbreviations } \\
\text { or write words in full. } \\
\text { Computerized order entry }\end{array}$ \\
\hline 3.1.3 & $\mathrm{C}_{1,2}$ & Check omitted/ incomplete & $\begin{array}{l}\text { Wrong drug and/ or wrong dose } \\
\text { would be delivered }\end{array}$ & & $2 \mathrm{C}$ & \\
\hline
\end{tabular}

ror as a high priority plan is recommended. It seems that high workload (50), long shifts (29) and quality of work (51) are the main factors that contributed to many errors in our study. Based on an extensive study in 617 hospitals, of which 488 were located in the United States and 12 in European countries, respectively, it was revealed that work organization of correlated with the quality of work environment in nursing (52). Another study on nurses in Belgium 
found that making improvements in nurses' attitude increased their decision-making power, and created an honest environment based on common values as well as active participation of the head nurses, leading to performing the nursing tasks more accurately with the least number of errors (51). However, checking the status of patients and medical procedures can help control and improve conditions (53).

Reporting clinical errors is a crucial element in creating safer healthcare systems (46). Thus, improving errorreporting system is an essential step to improve patient safety (54). Researchers found that only $10 \%$ of medical errors are reported (55) and only 3.5\% of the nurses believe that they should report all medical errors (56). A study on Iranian nurses showed that the number of errors that occurred was much more than what was reported (49). Ehsani et al. showed that $72.7 \%$ of the nurses did not report medical errors to their superiors (33). Their failure to report was due to the fear of fines or negative reaction of the patients (57). It seems that voluntary reporting of errors should be one of the common strategies. Creating computer based error reporting systems (42), job responsibility, organizational honesty, and learning from errors increase the number of reported errors (58). Moreover, equipment and tools can increase the human error rates considerably (59).

We are hopeful to detect and prevent the occurrence of errors and their great consequences. According to previous studies, $70 \%$ of the medical errors are preventable (42). The concept of integrated human factors and ergonomics (HFE) has been introduced as one of the key factors to help reduce medical errors (60). Based on the literature, controlling human error in medical environments is associated with human factors and ergonomics in the design and implementation of technologies, processes, workflows, jobs, teams and sociotechnical systems (61). Taking into account human factors and ergonomics increases the quality of healthcare services and patient safety (62). Application of information technology, organizational and work design (63), electronic records and health care/treatment data entry (64), social interactions, standard teamwork, and medical technologies are impressive cases in this challenging field (65).

\subsection{Conclusions}

In general, about 1.78 errors were detected for every studied task given in the infectious diseases ward. Considering the high level of errors, together with the sensitivity and the difficulty of patients' status in infectious conditions, it is mandatory to implement medical error management systems. Based on the findings of this study, it is highly recommended to redesign treatment protocols and medical procedures based on principles of human factors and ergonomics (HFE) to enhance the quality of services, improve patient safety and reduce medical errors.

\section{Acknowledgments}

The authors would like to appreciate all the managers and the entire staff of the hospital for their gracious cooperation. The authors declare that there is no conflict of interest.

\section{Footnotes}

Authors' Contribution: The overall implementation of this study, including design, data analysis, and manuscript preparation, was the result of joint efforts of all coauthors of this paper. All authors have made extensive contributions to the review and finalization of this manuscript.

Funding/Support: The study was a research project financially supported by the authors.

\section{References}

1. Kiassat AC. System Performance Analysis Considering Human-related Factors. University of Toronto; 2013.

2. Kallberg AS, Goransson KE, Florin J, Ostergren J, Brixey JJ, Ehrenberg A. Contributing factors to errors in Swedish emergency departments. Int Emerg Nurs. 2015;23(2):156-61. doi: 10.1016/j.ienj.2014.10.002. [PubMed: 25434782].

3. Stuart EH, Jarvis A, Daniel K. A ward without walls? District nurses' perceptions of their workload management priorities and job satisfaction. J Clin Nurs. 2008;17(22):3012-20. doi: 10.1111/j.13652702.2008.02316.x. [PubMed: 18647197]

4. Parry AM, Barriball KL, While AE. Factors contributing to registered nurse medication administration error: a narrative review. Int J Nurs Stud. 2015;52(1):403-20. doi: 10.1016/j.ijnurstu.2014.07.003. [PubMed: 25443300]

5. MohammadNejad S, Hojjati H, Ehsani R. The amount and type of medication errors in nursing students in four teaching hospitals of Tehran. Journal of Medical Ethics and History the Winter. 2008;88.

6. The health foundation. The measurement and monitoring of safety. London: The health foundation; 2013.

7. Lawton R, McEachan RR, Giles SJ, Sirriyeh R, Watt IS, Wright J. Development of an evidence-based framework of factors contributing to patient safety incidents in hospital settings: a systematic review. BMJ Qual Saf. 2012;21(5):369-80. doi: 10.1136/bmjqs-2011-000443. [PubMed: 22421911].

8. Cousins DH, Gerrett D, Warner B. A review of medication incidents reported to the National Reporting and Learning System in England and Wales over 6 years (2005-2010). BrJClin Pharmacol. 2012;74(4):597604. doi: 10.1111/j.1365-2125.2011.04166.x. [PubMed: 22188210].

9. Leufer T, Cleary-Holdforth J. Let's do no harm: medication errors in nursing: part 1. Nurse Educ Pract. 2013;13(3):213-6. doi: 10.1016/j.nepr.2013.01.013. [PubMed: 23474430].

10. Armitage G, Knapman H. Adverse events in drug administration: a literature review. J Nurs Manag. 2003;11(2):130-40. [PubMed:12581401]. 
11. Mrayyan MT, Shishani K, Al-Faouri I. Rate, causes and reporting of medication errors in Jordan: nurses' perspectives. J Nurs Manag. 2007;15(6):659-70. doi: 10.1111/j.1365-2834.2007.00724.x. [PubMed: 17688572].

12. Pham JC, Story JL, Hicks RW, Shore AD, Morlock LL, Cheung DS, et al. National study on the frequency, types, causes, and consequences of voluntarily reported emergency department medication errors. $J$ Emerg Med. 2011;40(5):485-92. doi: 10.1016/j.jemermed.2008.02.059. [PubMed: 18823735].

13. National Reporting and Learning Service (NRLS) . Organization patient safety incident reports 2014. Available from: http://www.nrls.npsa.nhs.uk/patient-safety-data/organisationpatient-safety-incident-reports/.

14. Institute of Medicine. To err is human. Building a safer health system. Washington: National Academy Press; 2000.

15. Ross LM, Wallace J, Paton JY. Medication errors in a paediatric teaching hospital in the UK: five years operational experience. Arch Dis Child. 2000;83(6):492-7. [PubMed: 11087283].

16. Drews FA, Musters A, Markham B, Samore MH, editors. Error producing conditions in the intensive care unit. Proceedings of the Human Factors and Ergonomics Society Annual Meeting. 2007; SAGE Publications; pp. 702-6.

17. Lane R, Stanton NA, Harrison D. Applying hierarchical task analysis to medication administration errors. Appl Ergon. 2006;37(5):669-79. doi: 10.1016/j.apergo.2005.08.001. [PubMed: 16182230].

18. Bates DW, Boyle DL, Vander Vliet MB, Schneider J, Leape L. Relationship between medication errors and adverse drug events.J Gen Intern Med. 1995;10(4):199-205. [PubMed: 7790981].

19. Freund Y, Goulet H, Bokobza J, Ghanem A, Carreira S, Madec D, et al. Factors associated with adverse events resulting from medical errors in the emergency department: two work better than one. J Emerg Med. 2013;45(2):157-62. doi: 10.1016/j.jemermed.2012.11.061. [PubMed: 23433610].

20. Unver V, Tastan S, Akbayrak N. Medication errors: perspectives of newly graduated and experienced nurses. Int $J$ Nurs Pract. 2012;18(4):317-24. doi: 10.1111/j.1440-172X.2012.02052.x. [PubMed: 22845630].

21. Rathert C, May DR. Health care work environments, employee satisfaction, and patient safety: Care provider perspectives. Health Care Manage Rev. 2007;32(1):2-11. [PubMed:17245197].

22. Fasolino T, Snyder R. Linking nurse characteristics, team member effectiveness, practice environment, and medication error incidence. $J$ Nurs Care Qual. 2012;27(2):E9-16. doi: 10.1097/NCQ.ob013e318241da17. [PubMed: 22218262].

23. Vogus TJ, Sutcliffe KM. The impact of safety organizing, trusted leadership, and care pathways on reported medication errors in hospital nursing units. Med Care. 2007;45(10):997-1002. doi: 10.1097/MLR.ob013e318053674f. [PubMed: 17890998].

24. Westbrook JI, Rob MI, Woods A, Parry D. Errors in the administration of intravenous medications in hospital and the role of correct procedures and nurse experience. BMJ Qual Saf. 2011;20(12):1027-34. doi: 10.1136/bmjqs-2011-000089. [PubMed: 21690248].

25. Westbrook JI, Woods A, Rob MI, Dunsmuir WT, Day RO. Association of interruptions with an increased risk and severity of medication administration errors. Arch Intern Med. 2010;170(8):683-90. doi: 10.1001/archinternmed.2010.65. [PubMed: 20421552].

26. Manojlovich M, DeCicco B. Healthy work environments, nursephysician communication, and patients' outcomes. Am J Crit Care. 2007;16(6):536-43. [PubMed: 17962497].

27. Mark BA, Belyea M. Nurse staffing and medication errors: cross-sectional or longitudinal relationships? Res Nurs Health. 2009;32(1):18-30. doi: 10.1002/nur.20305. [PubMed: 18825733].

28. Picone DM, Titler MG, Dochterman J, Shever L, Kim T, Abramowitz P, et al. Predictors of medication errors among elderly hospitalized patients. Am JMed Qual. 2008;23(2):115-27. doi:10.1177/1062860607313143. [PubMed: 18305099].
29. Clendon J, Gibbons V. $12 \mathrm{~h}$ shifts and rates of error among nurses: A systematic review. Int J Nurs Stud. 2015;52(7):1231-42. doi: 10.1016/j.ijnurstu.2015.03.011. [PubMed: 25910955].

30. Carlton G, Blegen MA. Medication-related errors: a literature review of incidence and antecedents. Annu Rev Nurs Res. 2006;24:19-38. [PubMed: 17078409].

31. Penjvini S. Investigation of the rate and type of medication errors of nurses in Sanandaj Hospitals. Iran J Nurs Res. 2006;1(1):59-64.

32. Cheragi MA, Manoocheri H, Mohammadnejad E, Ehsani SR. Types and causes of medication errors from nurse's viewpoint. Iran J Nurs Midwifery Res. 2013;18(3):228-31. [PubMed: 23983760].

33. Ehsani SR, Cheraghi MA, Nejati A, Salari A, Esmaeilpoor AH, Nejad EM. Medication errors of nurses in the emergency department. J Med Ethics Hist Med. 2013;6:11. [PubMed: 24427488].

34. Mohammadfam I, Movafagh M, Soltanian A, Salavati M, Bashirian S. Identification and Evaluation of Human Errors among the nurses of Coronary Care Unit Using CREAM Techniques.J Ergon. 2014;2(1):27-35.

35. Kermani A, Mazloumi A, Kazemi Z. Using SHERPA technique to analyze errors of health care staff working in emergency ward of Amiralmomenin hospital, Semnan. Iran Occup Health. 2015;12(2):13-23.

36. Habibi E, Garbe G, Reasmanjeyan M, Hasanzadah E. Human error assessment and management in Isfahan oil refinery work station operators by Sherpa technique. Injury Prevent. 2012;18(Suppl 1):A229.

37. Imtiaz M, Munsi A, Nayan D, Dei S. Systematic human error reduction and prediction approach while drilling. Int J Sci Engin Res. 2014;5(12):808-13.

38. Bligard LO, Osvalder AL. Predictive use error analysis-Development of AEA, SHERPA and PHEA to better predict, identify and present use errors. Int J Indust Ergon. 2014;44(1):153-70.

39. Harris D, Stanton NA, Marshall A, Young MS, Demagalski J, Salmon P. Using SHERPA to predict design-induced error on the flight deck. Aerospace Sci Technol. 2005;9(6):525-32.

40. Kermani A, Mazloumi A, NaslSeraji J, GhasemZadeh F. Identification and evaluation of human errors using SHERPA technique among nurses at emergency ward of an educational hospital in Semnan city, Iran. Occup Med Quart J. 2013;4(4):29-43.

41. Donchin Y, Gopher D, Olin M, Badihi Y, Biesky M, Sprung CL, et al. A look into the nature and causes of human errors in the intensive care unit. Crit Care Med. 1995;23(2):294-300. [PubMed: 7867355].

42. Mazloumi A, Kermani A, NaslSeraji J, GhasemZadeh F. Identification and evaluation of human errors of physicians at emergency ward of an educational hospital in Semnan city using SHERPA technique. Occup Med QJ. 2013;5(3):67-78.

43. Salmon P, Stanton NA, Gibbon A, Jenkins D, Walker GH. Human factors methods and sports science: A practical guide. CRC Press; 2009.

44. Stanton NA, Baber C. Validating task analysis for error identification: reliability and validity of a human error prediction technique. Ergonomics. 2005;48(9):1097-113. doi: 10.1080/00140130500219726. [PubMed: 16251150].

45. Mohammadfam I, Saeidi C. Evaluating human errors in cataract surgery using the SHERPA technique.J Ergon. 2015;2(4):41-7.

46. Hwang JI,Ahn J. Teamwork and clinical error reporting among nurses in Korean hospitals. Asian Nurs Res (Korean Soc Nurs Sci). 2015;9(1):1420. doi: 10.1016/j.anr.2014.09.002. [PubMed: 25829205].

47. Tanha F, Mazloumi A, Faraji V, Kazemi Z, Shoghi M. Evaluation of human errors, using Standardized Plant Analysis Risk Human Reliability Analysis technique, among nurses of delivery emergency ward of one of the Tehran University of Medical Sciences hospitals. J Hospital. 2015;14(3):57-66.

48. Kristensen S, Mainz J, Bartels P. A patient safety vocabulary: Safety Improvement for Patients in Europe. Aarhus: The ESQH-Office for Quality Indicators; 2007.

49. Hajibabaee F, Joolaee S, Peyravi H, Alijany-Renany H, Bahrani N, Haghani H. Medication error reporting in Tehran: a survey. $J$ Nurs Manag. 2014;22(3):304-10. doi: 10.1111/jonm.12226. [PubMed: 
24612424].

50. Leiter MP, Maslach C. Nurse turnover: the mediating role of burnout. J Nurs Manag. 2009;17(3):331-9. doi: 10.1111/j.1365-2834.2009.01004.x. [PubMed: 19426369].

51. Van Bogaert P, Kowalski C, Weeks SM, Van Heusden D, Clarke SP. The relationship between nurse practice environment, nurse work characteristics, burnout and job outcome and quality of nursing care: a cross-sectional survey. Int J Nurs Stud. 2013;50(12):1667-77. doi: 10.1016/j.ijnurstu.2013.05.010. [PubMed: 23777786].

52. Aiken LH, Sermeus W, Van den Heede K, Sloane DM, Busse R, McKee M, et al. Patient safety, satisfaction, and quality of hospital care: cross sectional surveys of nurses and patients in 12 countries in Europe and the United States. BMJ. 2012;344:ee1717. doi: 10.1136/bmj.e1717. [PubMed: 22434089].

53. Jones A, Johnstone MJ, Duke M. 'Hands-on' assessment: A useful strategy for improving patient safety in emergency departments. Australas Emerg Nurs J. 2015;18(4):212-7. doi: 10.1016/j.aenj.2015.07.002. [PubMed: 26300414].

54. Sanghera IS, Franklin BD, Dhillon S. The attitudes and beliefs of healthcare professionals on the causes and reporting of medication errors in a UK Intensive care unit. Anaesthesia. 2007;62(1):53-61. doi: 10.1111/j.1365-2044.2006.04858.x. [PubMed: 17156227].

55. Serembus J, Wolf ZR, Youngblood N. Consequences of fatal medication errors for health care providers 2011. Available from: http://hdl. handle.net/10755/163465.

56. Chiang HY, Pepper GA. Barriers to nurses' reporting of medication administration errors in Taiwan. J Nurs Scholarsh. 2006;38(4):392-9. [PubMed: 17181090].

57. Mason DJ. To forgive, divine: it's time to drop the veil of secrecy about disclosing errors. Am J Nurs. 2005;105(12):11. [PubMed: 16327361].

58. Hewitt T, Chreim S, Forster A. Sociocultural Factors Influencing In cident Reporting Among Physicians and Nurses: Understanding Frames Underlying Self- and Peer-Reporting Practices. J Patient Saf 2014 doi: 10.1097/PTS.0000000000000130. [PubMed: 25119783].

59. Dhillon BS. Human reliability, error, and human factors in engineering maintenance: with reference to aviation and power generation. CRC Press; 2009.

60. Institute of Medicine . Preventing medication errors. Washington DC: The National Academies Press; 2006.

61. Carayon P, Xie A, Kianfar S. Human factors and ergonomics as a patient safety practice. BMJ Qual Saf. 2014;23(3):196-205. doi: 10.1136/bmjqs-2013-001812. [PubMed: 23813211].

62. Carayon P, Smith P, Hundt AS, Kuruchittham V, Li Q. Implementation of an electronic health records system in a small clinic: the viewpoint of clinic staff. Behav InfTechnol. 2009;28(1):5-20.

63. Carayon P, Kianfar S, Li Y, Wooldridge A. Organizational design: Macroergonomics as a foundation for human systems integration. Washington: American Psychological Association; 2015.

64. Holden RJ, Carayon P, Gurses AP, Hoonakker P, Hundt AS, Ozok AA, et al. SEIPS 2.0: a human factors framework for studying and improving the work of healthcare professionals and patients. Ergonomics. 2013;56(11):1669-86. doi: 10.1080/00140139.2013.838643. [PubMed: 24088063].

65. Carayon P, Kianfar S, Li Y, Xie A, Alyousef B, Wooldridge A. A systematic review of mixed methods research on human factors and ergonomics in health care. Appl Ergon. 2015;51:291-321. doi: 10.1016/j.apergo.2015.06.001. [PubMed: 26154228]. 